\title{
Notch activation mediates angiotensin II-induced vascular remodeling by promoting the proliferation and migration of vascular smooth muscle cells
}

\author{
Yukako Ozasa $^{1}$, Hiroshi Akazawa ${ }^{2,3}$, Yingjie Qin ${ }^{1}$, Kaoru Tateno ${ }^{1}$, Kaoru Ito ${ }^{1}$, Yoko Kudo-Sakamoto ${ }^{2}$, \\ Masamichi Yano $^{2}$, Chizuru Yabumoto ${ }^{2}$, Atsuhiko T Naito ${ }^{3,4}$, Toru Oka ${ }^{2,3}$, Jong-Kook Lee ${ }^{3,4}$, Tohru Minamino ${ }^{5}$, \\ Toshio Nagai ${ }^{1}$, Yoshio Kobayashi ${ }^{1}$ and Issei Komuro ${ }^{2,3,6}$
}

Notch signaling is involved in an intercellular communication mechanism that is essential for coordinated cell fate determination and tissue morphogenesis. The biological effects of Notch signaling are context-dependent. We investigated the functional and hierarchical relationship between angiotensin (Ang) II receptor signaling and Notch signaling in vascular smooth muscle cells (VSMCs). A fluorogenic substrate assay revealed directly that the enzymatic activity of $\gamma$-secretase was enhanced after 10 min of Ang II stimulation in HEK293 cells expressing Ang II type 1 receptor. Notch cleavage by $\gamma$-secretase was consistently induced and peaked at $10 \mathrm{~min}$ after Ang II stimulation, and the Ang II-stimulated increase in Notch intracellular domain production was significantly suppressed by treatment with the $\gamma$-secretase inhibitor DAPT. Treatment with DAPT also significantly reduced the Ang II-stimulated proliferation and migration of human aortic VSMCs, as revealed by BrdU incorporation and the Boyden chamber assay, respectively. Systemic administration of the $\gamma$-secretase inhibitor dibenzazepine reduced Ang II-induced medial thickening and perivascular fibrosis in the aortas of wild-type mice. These findings suggest that the hierarchical Ang II receptor-Notch signaling pathway promotes the proliferation and migration of VSMCs, and thereby contributes to the progression of vascular remodeling. Hypertension Research (2013) 36, 859-865; doi:10.1038/hr.2013.52; published online 30 May 2013

Keywords: angiotensin II; $\gamma$-secretase; Notch signaling; vascular remodeling; vascular smooth muscle cell

\section{INTRODUCTION}

Both the renin-angiotensin system (RAS) and the Notch signaling pathway exhibit pleiotropic effects on the structure and function of multiple organ systems. RAS not only plays a homeostatic role in the regulation of blood pressure and the balance of sodium and water, but also has diverse pathological effects on the heart and vessels. ${ }^{1}$ Angiotensin II (Ang II) is the primary bioactive molecule of RAS, and most of the pathophysiological actions of Ang II in the cardiovascular system are mediated primarily through the Ang II type $1\left(\mathrm{AT}_{1}\right)$ receptor. $^{2}$ The $\mathrm{AT}_{1}$ receptor is a seven-transmembrane spanning G-protein-coupled receptor (GPCR), and activation of $\mathrm{AT}_{1}$ receptor elicits multiple cellular responses via G-protein-dependent and -independent signaling pathways. ${ }^{3,4}$ The principal targets of Ang II in the vasculature are vascular smooth muscle cells (VSMCs), and $\mathrm{AT}_{1}$ receptor activation stimulates growth, proliferation and migration of VSMCs via the mitogen-activated protein kinase pathway. ${ }^{4-6} \mathrm{AT}_{1}$ receptor activation also stimulates vascular fibrosis by enhancing synthesis and deposition of the extracellular matrix protein via transactivation of epidermal growth factor receptor and generation of reactive oxygen species. ${ }^{4,7}$ In spite of the central role of $\mathrm{AT}_{1}$ receptor signaling in multiple vascular pathobiological processes, the full scope of the specific signal transduction pathways leading to vascular remodeling remains to be fully elucidated.

The Notch signaling pathway plays a fundamental role in cell fate determination, differentiation, proliferation and apoptosis during diverse developmental and physiological processes. ${ }^{8,9}$ Binding of Notch ligands to the surfaces of neighboring cells triggers sequential proteolytic cleavage of the transmembrane Notch receptor by ADAMfamily metalloproteases and the $\gamma$-secretase complex to release the Notch intracellular domain (NICD) into the cytoplasm. ${ }^{8-10}$ Once cleaved, NICD migrates into the nucleus, and forms a complex with the DNA-binding protein RBP-J $\kappa$, the co-activator mastermind-like (MAML) and other co-activators to further activate the transcription of target genes. ${ }^{8-10}$ It has been reported that Notch signaling controls

\footnotetext{
${ }^{1}$ Department of Cardiovascular Science and Medicine, Chiba University Graduate School of Medicine, Chiba, Japan; ${ }^{2}$ Department of Cardiovascular Medicine, Osaka University Graduate School of Medicine, Suita, Japan; ${ }^{3}$ CREST, Japan Science and Technology Agency, Tokyo, Japan; ${ }^{4}$ Department of Cardiovascular Regenerative Medicine, Osaka University Graduate School of Medicine, Suita, Japan; ${ }^{5}$ Department of Cardiovascular Biology and Medicine, Niigata University Graduate School of Medical and Dental Sciences, Niigata, Japan and ${ }^{6}$ Department of Cardiovascular Medicine, Graduate School of Medicine, the University of Tokyo, Tokyo, Japan

Correspondence: Dr I Komuro, Department of Cardiovascular Medicine, Graduate School of Medicine, the University of Tokyo, 7-3-1 Hongo, Bunkyo-ku, Tokyo 113-8655, Japan. E-mail: komuro-tky@umin.ac.jp

Received 22 February 2013; revised 1 March 2013; accepted 5 March 2013; published online 30 May 2013
} 
proliferation and phenotypic switching of VSMCs after vascular injury, as well as the embryonic developmental program of the vasculature. ${ }^{11,12}$

We investigated the role of the functional and hierarchical relationship between $\mathrm{AT}_{1}$ receptor signaling and Notch signaling in the pathogenesis of vascular remodeling. We found that Ang II stimulated the enzymatic activity of $\gamma$-secretase and thereby activated the Notch signaling pathway. The pharmacological inhibition of $\gamma$-secretase significantly reduced not only Ang II-stimulated proliferation and migration of VSMCs in vitro but also Ang II-induced aortic medial thickening and perivascular fibrosis in vivo. These results provide mechanistic insights into the hierarchical Ang II receptor-Notch signaling pathway that contributes to the progression of vascular remodeling.

\section{METHODS}

\section{Cell cultures}

HEK293 cells expressing the $\mathrm{AT}_{1}$ receptor (HEK293-AT cells) $^{13,14}$ were cultured in Dulbecco's modified Eagle's medium supplemented with $10 \%$ fetal bovine serum, and were starved under a serum-free condition for $48 \mathrm{~h}$ before stimulation with $10^{-7}$ M Ang II (Sigma-Aldrich, St Louis, MO, USA). Human aortic smooth muscle cells (AoSMCs) were purchased from Lonza (Basel, Switzerland) and routinely cultured in smooth muscle medium-2 (SmGM-2, Lonza,) containing 5\% fetal bovine serum with growth factors and antibiotics (SmGM-2 Bullet Kit, Lonza). AoSMCs were starved under a serum-free condition for $48 \mathrm{~h}$ before stimulation with $10^{-6} \mathrm{M}$ Ang II. The $\gamma$-secretase inhibitor $N$-[N-(3,5-difluorophenacetyl-L-alanyl)]$S$-phenylglycine $t$-butyl ester (DAPT) was from Calbiochem (La Jolla, CA, USA). Actinomycin D and cycloheximide were from Sigma-Aldrich. The experiments were repeated at least three times in triplicate, and representative data are shown.

\section{Western blot analysis}

Nuclear extract was isolated using NE-PER Nuclear and Cytoplasmic Extraction Reagents (Pierce Biotechnology, Rockford, IL, USA), according to the manufacturer's instructions. Protein samples were fractionated with SDS-PAGE and transferred to PVDF membranes (GE Healthcare Biosciences, Piscataway, NJ, USA). The blotted membranes were incubated with primary antibody and then with horseradish peroxidase-conjugated secondary antibody (Jackson ImmunoResearch Laboratories, West Grove, PA, USA). Immunoreactive signals were visualized using an ECL Plus Western Blotting Detection System (GE Healthcare Biosciences). The following antibodies were used: rabbit polyclonal anti-NOTCH 1 (Cleaved N Terminal) antibody (Rockland Immunochemicals, Gilbertsville, PA, USA), rabbit polyclonal anti-cleaved Notch1 (Val1744) antibody (Cell Signaling Technology, Beverly, MA, USA), goat polyclonal anti-DNA topoisomerase I (Topo I) (Santa Cruz Biotechnology, Santa Cruz, CA, USA) and mouse monoclonal anti-nucleoporin p62 (BD Transduction Laboratories, San Diego, CA, USA).

\footnotetext{
$\gamma$-Secretase-mediated peptide cleavage assay

The cells were homogenized in lysis buffer ( $25 \mathrm{~mm}$ Tris- $\mathrm{HCl}, \mathrm{pH}$ 7.4, $25 \mathrm{~mm}$ $\mathrm{NaCl}, 0.5 \mathrm{~mm}$ EGTA) plus protease inhibitors (Complete mini; Roche Applied Science, Indianapolis, IN, USA), and lysates were centrifuged at $800 \mathrm{~g}$ for $10 \mathrm{~min}$ to pellet unbroken cells and nuclei. The supernatant was discarded, and the pellets were resuspended in assay buffer $(50 \mathrm{~mm}$ Tris- $\mathrm{HCl}, \mathrm{pH} 6.8,2 \mathrm{~mm}$ EDTA, $0.25 \%$ CHAPSO). The protein $(15 \mu \mathrm{g})$ was incubated at $37^{\circ} \mathrm{C}$ in assay buffer containing $8 \mu \mathrm{M}$ fluorogenic $\gamma$-secretase substrate (Calbiochem). After incubation, the reaction mixtures were centrifuged at $16100 \mathrm{~g}$ for $15 \mathrm{~min}$ and placed on ice. The supernatants were transferred to a 96-well plate, and fluorescence was measured using a microplate reader (FlexStation 3; Molecular Devices, Sunnyvale, CA, USA) with excitation wavelength $355 \mathrm{~nm}$ and emission wavelength $440 \mathrm{~nm}$. The slope of the linear range was correlated with $\gamma$-secretase activity after subtraction of the nonspecific signal.
}

\section{Luciferase assays}

The luciferase reporter plasmids were transfected using FuGENE HD Transfection Reagent (Roche Applied Science) according to the manufacturer's instructions. pRL-SV40 (Promega, Madison, WI, USA) was co-transfected as an internal control. Luciferase activities were measured $24 \mathrm{~h}$ after Ang II stimulation using a dual-luciferase reporter assay system (Promega). The experiments were repeated at least three times in triplicate, and representative data are shown. The luciferase reporter plasmids were generous gifts from Dr T Honjo (Kyoto University), M Kengaku (RIKEN Brain Science Institute) $\left(R B P-J \kappa-\right.$ Luc $\left.^{15}\right)$ and Dr R Kageyama (Kyoto University) (Hes1-Luc and Hes5-Luc $\left.{ }^{16}\right)$.

\section{Proliferation and migration assays}

Cell proliferation was measured by bromodeoxyuridine (BrdU) incorporation during DNA synthesis of proliferating cells using a Cell Proliferation ELISA Kit (Roche Applied Science). After $48 \mathrm{~h}$ of incubation at $37^{\circ} \mathrm{C}$ in serum-free medium, AoSMCs were labeled with BrdU with or without $10^{-6} \mathrm{M}$ Ang II for $8 \mathrm{~h}$. DNA synthesis was assayed by measuring the amount of BrdU incorporation according to the manufacturer's instructions. Cell migration was measured using Transwell 24-well plates (Corning Costar 3422; Corning Inc., Corning, NY, USA) with an 8 - $\mu \mathrm{m}$-pore polycarbonate membrane. The underside of the polycarbonate membrane was coated with $50 \mu \mathrm{g} \mathrm{ml}^{-1}$ collagen type I (Cellmatrix; Nitta Gelatin Inc., Osaka, Japan) overnight at $4{ }^{\circ} \mathrm{C}$. AoSMCs (passage 7-10) were plated on the upper well at 5000 cells per well. After incubation in SmGM-2 with a SmGM-2 Bullet Kit for $48 \mathrm{~h}$, the cells were washed in PBS twice and starved in Dulbecco's modified Eagle's medium supplemented with $0.2 \%$ fetal bovine serum for $24 \mathrm{~h}$. The cells were pretreated with DAPT $\left(2 \times 10^{-5} \mathrm{M}\right)$ or vehicle for $30 \mathrm{~min}$, and placed in the lower chamber in the presence or absence of $10^{-6} \mathrm{M}$ Ang II. After $6 \mathrm{~h}$ of incubation at $37^{\circ} \mathrm{C}$, the cells on the upper surface were washed, fixed and stained with hematoxylin and eosin. The number of cells that migrated to the lower (outer) surface of the filters was determined by counting under a microscope.

\section{Ang II infusion and histological analysis}

Twelve-week-old C57BL/6J male mice were treated with Ang II $\left(0.9 \mathrm{mg} \mathrm{kg}^{-1}\right.$ per day) or vehicle for 2 weeks using an osmotic mini-pump (ALZET model 2002; Durect Corp., Cupertino, CA, USA), as described previously. ${ }^{17}$ The mice were randomly assigned to orally receive vehicle alone (0.4\% methylcellulose) or the $\gamma$-secretase inhibitor dibenzazepine $\left(1.0 \mathrm{mg} \mathrm{kg}^{-1}\right.$ per day; Santa Cruz Biotechnology $)^{18}$ during Ang II infusion. The abdominal aortas were excised, fixed immediately in $10 \%$ neutralized formalin, and embedded in paraffin. Serial sections (thickness $5 \mu \mathrm{m}$ ) were stained with hematoxylin and eosin for morphological analysis, or with Masson's trichrome for detection of fibrosis. To evaluate aortic wall thickness and perivascular fibrosis, short-axis images were scanned at $\times 200$ magnification. The medial thickness, wall to lumen ratio (the ratio of medial thickness to internal diameter) and area of perivascular fibrosis (the ratio of the fibrotic area surrounding the vessel to the total vessel area) were calculated. All protocols were approved by the Institutional Animal Care and Use Committee of Chiba University.

\section{Real time RT-PCR analysis}

Total RNA was extracted using an RNeasy Kit (Qiagen, Valencia, CA, USA), and single-stranded cDNA was transcribed using a SuperScript VILO cDNA Synthesis Kit (Invitrogen, Carlsbad, CA, USA), according to the manufacturer's protocols. We conducted quantitative real-time PCR analysis using Universal ProbeLibrary Assays (Roche Applied Science) according to the manufacturer's instructions. The amplification conditions were initial denaturation for $10 \mathrm{~min}$ at $95^{\circ} \mathrm{C}$ followed by 45 cycles of $10 \mathrm{~s}$ at $95^{\circ} \mathrm{C}$ and $25 \mathrm{~s}$ at $60^{\circ} \mathrm{C}$. Individual PCR products were analyzed by melting point analysis. The expression level of a gene was normalized relative to that of GAPDH using a comparative Ct method. The primer sequences and Universal Probe numbers were designed using ProbeFinder software (Roche Applied Science) as follows: NOTCH1, 5' CGCACAAGGTGTCTTCCAG- $3^{\prime}$ and $5^{\prime}$-AGGATCAGTGGCGTCGTG- ${ }^{\prime}$, No 85; $\mathrm{NOTCH} 2,5^{\prime}$-GGCAGACTGGTGACTTCACTT- $3^{\prime}$ and $5^{\prime}$-CTCTCACAG GTGCTCCCTTC- $3^{\prime}$, No. 8; NOTCH3 3 , ${ }^{\prime}$-GCCAAGCGGCTAAAGGTA- $3^{\prime}$ and 5'-CACTGACGGCAATCCACA-3', No. 30; NOTCH4, 5'-CCTCTCTGCAA 
CCTTCCACT- $3^{\prime}$ and $5^{\prime}$-GCCTCCATTGTGGCAAAG-3' ${ }^{\prime}$, No. 51; JAG1, 5'-GA ATGGCAACAAAACTTGCAT- $3^{\prime}$ and $5^{\prime}$-AGCCTTGTCGGCAAATAGC- $3^{\prime}$, No. 42; JAG2, $5^{\prime}$-TGGGACTGGGACAACGATAC- $3^{\prime}$ and $5^{\prime}$-ATGCGACACTCGC TCGAT- ${ }^{\prime}$, No. 17; DLL1, $5^{\prime}$-CTTCCCCTTCGGCTTCAC-3' ${ }^{\prime}$ and $5^{\prime}$-GGGTT TTCTGTTGCGAGGT-3', No. 2; DLL3, 5'-CAACTGTGAGAAGAGGGTGGA$3^{\prime}$ and $5^{\prime}$-CCAGGTCCAGGCAGAGTC-3' ${ }^{\prime}$, No. 46; DLL4, 5'-CCCTGGCAATG TACTTGTGAT- $3^{\prime}$ and $5^{\prime}$-TGGTGGGTGCAGTAGTTGAG-3' ${ }^{\prime}$, No. 23; GAPDH, $5^{\prime \prime}$-AGCCACATCGCTCAGACAC- $3^{\prime}$ and $5^{\prime}$-GCCCAATACGACCAAATCC- $3^{\prime}$, No. 60.

\section{Statistics}

All data are presented as means \pm s.e.m. Two-group comparisons were performed using unpaired two-tailed Student's $t$ test, and multiple-group comparisons were performed by a one-way ANOVA followed by Fisher's PLSD test for comparison of means. A $P$ value $<0.05$ was considered to be statistically significant.

\section{RESULTS}

Ang II stimulation induces nuclear accumulation of NICD in HEK293 cells expressing the $\mathrm{AT}_{1}$ receptor

To elucidate the functional and hierarchical relationship between $\mathrm{AT}_{1}$ receptor signaling and Notch signaling, we examined the timedependent changes of nuclear NICD levels in HEK293-AT 1 cells after stimulation with Ang II. HEK293 cells possess functional GPCR signaling pathways without detectable expression of the $\mathrm{AT}_{1}$ receptor. ${ }^{19}$ Western blot analysis using an antibody specific to NICD revealed that nuclear NICD levels increased and peaked at $10 \mathrm{~min}$ after Ang II stimulation (Figure 1a). These results suggest that activation of the $\mathrm{AT}_{1}$ receptor induces nuclear accumulation of NICD.

\section{Ang II stimulation activates Notch signaling via the enhancement} of $\gamma$-secretase activity

As the nuclear accumulation of NICD may have resulted from enhanced proteolysis of Notch protein by $\gamma$-secretase, ${ }^{10}$ we examined the effect of Ang II stimulation on $\gamma$-secretase activity in HEK293-AT 1 cells. We measured the enzymatic activity of $\gamma$-secretase directly using a fluorogenic substrate assay ${ }^{20}$ and found that $\gamma$-secretase activity was significantly enhanced $10 \mathrm{~min}$ after stimulation with Ang II, and that the enhancing effect was suppressed by treatment with the $\gamma$-secretase inhibitor DAPT (Figure 1b). Ang II-induced nuclear accumulation of NICD was consistently reduced by treatment with DAPT (Figure 1c).

To elucidate the functional importance of the Ang II-induced increase in nuclear NICD, we examined Notch-dependent activation of luciferase-based reporters. Ang II strongly enhanced luciferase activity driven by the Notch-dependent CBF1-responsive element (RBP-J $\kappa$-Luc), Hes1 promoter (Hes1-Luc) and Hes5 promoter (Hes5Luc) in HEK293-AT 1 cells (Figures 1d-f). The Ang II-induced transactivation of Notch-dependent reporters was significantly inhibited by treatment with DAPT (Figures 1d-f). These findings suggest that Ang II stimulation activates Notch signaling via the enhancement of $\gamma$-secretase activity. a

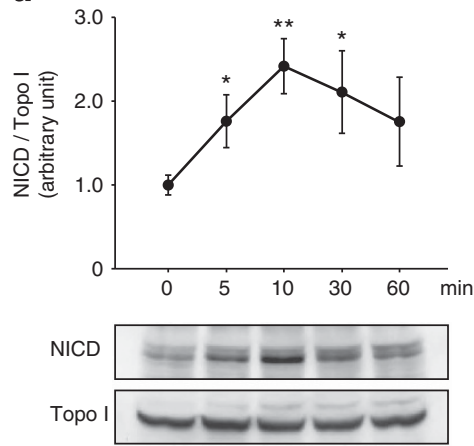

d HEK293-AT $:$ RBPjK-LuC

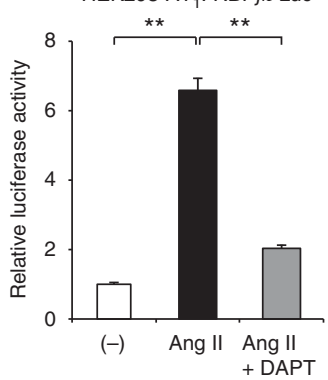

b

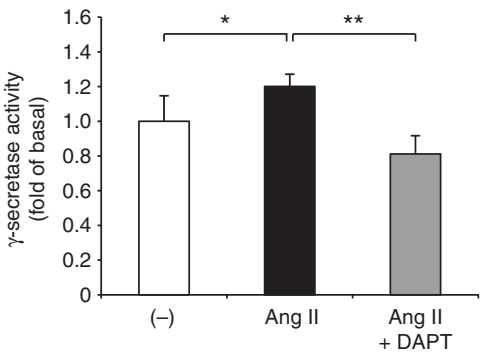

C

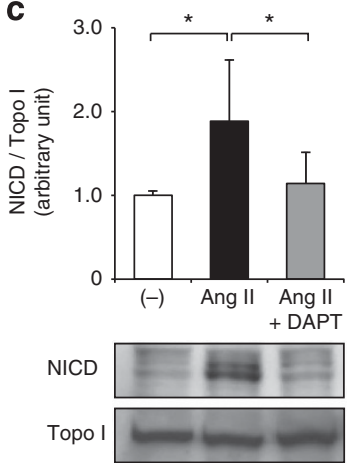

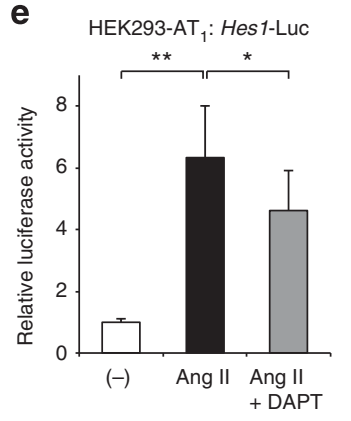

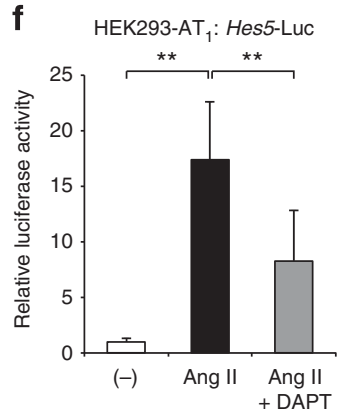

Figure 1 Ang II stimulates $\gamma$-secretase and activates Notch signaling in HEK293-AT ${ }_{1}$ cells. (a) HEK293-AT ${ }_{1}$ cells were stimulated with Ang II (10-7 ${ }^{-1}$ ) for the indicated periods, and NICD protein in the nuclear fraction was visualized by immunoblotting. Topo I was used as an internal control for the amount of nuclear protein. The NICD/Topo I ratios were quantified by densitometry and plotted (upper panel). The data are presented as the mean \pm s.e.m. ${ }^{*} P<0.05$, ${ }^{*} P<0.01$ vs. the value at 0 min. (b) HEK293-AT 1 cells were pretreated with DAPT and stimulated with Ang II $\left(10^{-7} \mathrm{M}\right)$ for $10 \mathrm{~min}$, and $\gamma$-secretase activity was determined using a fluorogenic substrate assay. The data are presented as the mean \pm s.e.m. ${ }^{*} P<0.05,{ }^{*} P<0.01$. (c) $\mathrm{HEK}^{*}$ - $93-\mathrm{AT}_{1}$ cells were pretreated with or without DAPT $\left(2 \times 10^{-5} \mathrm{M}\right)$ and stimulated with Ang $\mathrm{II}\left(10^{-7} \mathrm{M}\right)$ for $10 \mathrm{~min}$, and NICD and Topo I in the nuclear fraction were visualized by immunoblotting. The NICD/Topo I ratios were quantified and presented as a bar graph (upper panel). The data are presented as the mean \pm s.e.m. ${ }^{*} P<0.05$. (d-f) HEK293-AT 1 cells were transfected with RBPjk-luciferase reporter (d), Hes1-luciferase reporter (e) or Hes5-luciferase reporter (f). The cells were pretreated with or without DAPT $\left(2 \times 10^{-5} \mathrm{M}\right)$ and stimulated with Ang $\mathrm{II}\left(10^{-7} \mathrm{M}\right)$ for $24 \mathrm{~h}$ before the measurement of luciferase activities. The data are presented as the mean \pm s.e.m. ${ }^{*} P<0.05,{ }^{*} P<0.01$. 
Ang II stimulation activates Notch signaling independently of de novo synthesis of Notch receptors and ligands

As most Notch ligands are also transmembrane proteins, the propagation of Notch signaling is essentially restricted to neighboring cells. ${ }^{8-10}$ We considered the possibility that Notch signaling is enhanced as a consequence of the upregulation of Notch receptors and ligands by Ang II stimulation. However, in quantitative real-time RT-PCR analysis, the mRNA expression levels of Notch receptors (NOTCH1-4) and Notch ligands (JAG1, JAG2, DLL1, DLL3 and DLL4) in HEK293-AT 1 cells were not significantly changed following Ang II stimulation (Figure 2a). Ang II stimulation increased nuclear NICD levels in HEK293-AT 1 cells even in the presence of the transcription inhibitor actinomycin $\mathrm{D}$ or the translation inhibitor cycloheximide (Figure 2b). These findings suggest that de novo synthesis of Notch receptors and ligands is not involved in the process of hierarchical activation of the $\mathrm{AT}_{1}$ receptor-Notch signaling pathway.

\section{Notch signaling mediates Ang II-stimulated proliferation and migration of human AoSMCs}

We investigated the functional significance of Notch signaling in mediating the pathological actions of Ang II in VSMCs. In human AoSMCs, nuclear NICD levels increased and peaked at $30 \mathrm{~min}$ after Ang II stimulation (Figure 3a), indicating that Ang II stimulation activates Notch signaling in VSMCs as well as in HEK293-AT 1 cells. Ang II is an important growth factor for VSMCs, and Ang II stimulation significantly increased DNA synthesis in human AoSMCs as measured by incorporation of the nucleotide analog BrdU (Figure 3b). Ang II is also a potent chemoattractant for VSMCs, and Ang II stimulation significantly enhanced the migration of human AoSMCs as measured by a Boyden chamber assay (Figure 3c). The enhanced DNA synthesis and migration of AoSMCs in response to Ang II stimulation were significantly suppressed by treatment with DAPT (Figures $3 \mathrm{~b}$ and $\mathrm{c}$ ). These findings suggest that Notch signaling mediates the Ang II-induced enhancement of VSMC proliferation and migration.

\section{Notch signaling mediates Ang II-induced vascular remodeling in} mice

Ang II contributes to structural remodeling of the aorta, which is characteristic of the vascular damage in hypertension and atherosclerosis. Analysis of hematoxylin and eosin staining of tissue sections revealed that the medial thickness of the abdominal aorta of wild-type mice was increased 1.6-fold after 2 weeks of Ang II infusion (Figures $4 \mathrm{a}$ and $\mathrm{b}$ ). Masson's trichrome staining indicated that Ang II infusion induced perivascular fibrosis (Figure 4a). Systemic administration of the $\gamma$-secretase inhibitor dibenzazepine significantly reduced Ang IIinduced medial thickening and perivascular fibrosis in the aorta of mice (Figures $4 \mathrm{a}$ and $\mathrm{b}$ ). These findings suggest that Notch signaling mediates Ang II-induced vascular remodeling in mice.

\section{DISCUSSION}

The results of this study provide a more comprehensive insight into the role of $\mathrm{AT}_{1}$ receptor signaling in the pathogenesis of vascular remodeling and help clarify the mechanism of action of this pathway. Upon activation by Ang II, the $\mathrm{AT}_{1}$ receptor stimulates the Notch signaling pathway via the enhancement of $\gamma$-secretase enzymatic activity. Following such stimulation, Notch signaling promotes the
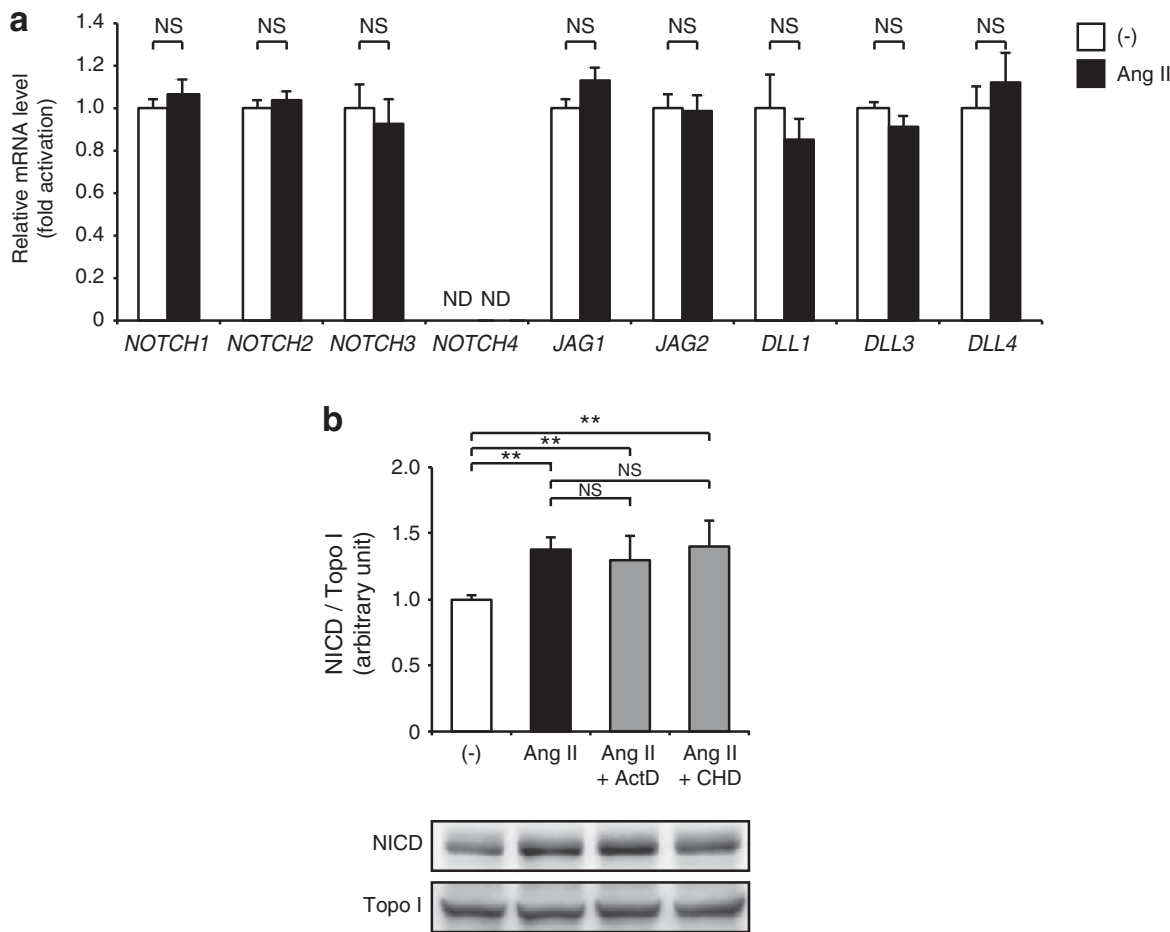

Figure 2 Ang II activates Notch signaling independently of the de novo synthesis of Notch receptors and ligands. (a) The mRNA expressions of NOTCH1, NOTCH2, NOTCH3, NOTCH4, JAG1, JAG2, DLL1, DLL3 and DLL4 in HEK293-AT 1 cells were determined 10 min after stimulation with Ang II (10-7 M) or $^{-1}$ vehicle. The experiments were repeated five times in duplicate. The data are presented as the mean \pm s.e.m. ND, not determined; NS, not significant. (b) HEK293-AT 1 cells were pretreated with or without actinomycin D $(1 \mu \mathrm{g} \mathrm{ml}-1)$ or cycloheximide $\left(7.5 \mu \mathrm{g} \mathrm{ml}{ }^{-1}\right)$ and stimulated with Ang II $\left(10^{-7} \mathrm{M}\right)$ for 10 min. NICD and Topo I in the nuclear fraction were visualized by immunoblotting. The NICD/Topo I ratios were quantified and presented as a bar graph (upper panel). The data are presented as the mean \pm s.e.m. ActD, actinomycin $\mathrm{D} ; \mathrm{CHD}$, cycloheximide; NS, not significant. ${ }^{* *} P<0.01$. 
proliferation and migration of VSMCs, and contributes to the progression of vascular remodeling, which is characterized by aortic medial thickening and perivascular fibrosis. Our results provide the
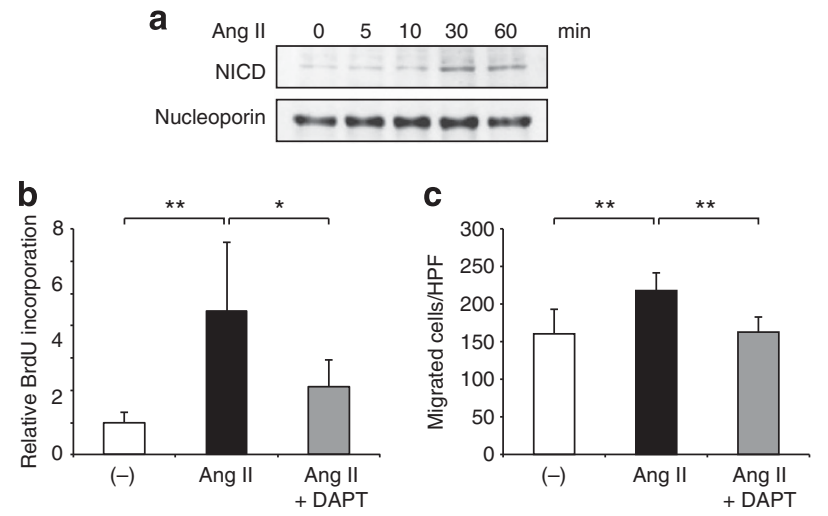

Figure 3 Ang II stimulates the proliferation and migration of human aortic SMCs via activation of Notch signaling. (a) AoSMCs were stimulated with Ang II $\left(10^{-7} \mathrm{M}\right)$ for the indicated periods, and NICD protein in the nuclear fraction was visualized by immunoblotting. Nucleoporin was used as an internal control for the amount of nuclear protein. (b) Effect of inhibiting Notch signaling on Ang II-induced proliferation of AoSMCs. Proliferation of AoSMCs following stimulation with Ang $\|\left(10^{-7} \mathrm{M}\right)$ in the presence or absence of DAPT $\left(2 \times 10^{-5} \mathrm{M}\right)$ was monitored by BrdU incorporation. The data are presented as the mean \pm s.e.m. ${ }^{*} P<0.05$, ${ }^{*} P<0.01$. (c) The effect of inhibiting Notch signaling on Ang II-induced migration of AoSMCs. The number of migrated AoSMCs in the presence or absence of DAPT $\left(2 \times 10^{-5} \mathrm{M}\right)$ was counted after stimulation with Ang II $\left(10^{-7} \mathrm{M}\right)$. The data are presented as the mean \pm s.e.m. ${ }^{* *} P<0.01$. first experimental evidence for hierarchical and functional crosstalk between two major signaling pathways, $\mathrm{AT}_{1}$ receptor signaling and Notch signaling.

It remains unclear how $\gamma$-secretase activity is enhanced as a consequence of $\mathrm{AT}_{1}$ receptor activation. It has been reported that the amplitude and duration of Notch signal activation can be influenced at various points of the pathway, depending on the cellular context, by the regulation of endocytosis, trafficking of ligands and receptors, ectodomain shedding by ADAM metalloprotease, intramembrane proteolysis by $\gamma$-secretase and stochastic binding of Notch ligands to Notch receptors. ${ }^{9}$ We found that de novo synthesis of Notch receptors and ligands was not involved in the activation of the $\mathrm{AT}_{1}$ receptor-Notch signaling pathway (Figure 2), and that the amplitude of Notch signal activation by $\mathrm{AT}_{1}$ receptor stimulation was unchanged when HEK293-AT 1 cells were cultured at various initial cell-seeding densities (Supplementary Figure S1). The direct measurement of $\gamma$-secretase activity revealed that $\gamma$-secretase enzymatic activity was enhanced following $\mathrm{AT}_{1}$ receptor stimulation (Figure $1 \mathrm{~b}$ ). We therefore speculate that $\mathrm{AT}_{1}$ receptor stimulation activates Notch signaling simply by enhancing the proteolytic activity of $\gamma$-secretase without any effect on the kinetics and dynamics of ligand-receptor binding. A previous study indicated that activation of the $\beta_{2}$-adrenergic receptor, a typical GPCR, stimulates $\gamma$-secretase activity and accelerates amyloid plaque formation. ${ }^{21}$ Such enhancement involves the association of $\beta_{2}$-adrenergic receptor with presenilin-1, and requires the agonist-induced endocytosis of $\beta_{2}$-adrenergic receptor and the trafficking of $\gamma$-secretase to late endosomes and lysosomes. ${ }^{21}$ It will be interesting to elucidate the precise molecular mechanism whereby activation of GPCRs leads to increased enzymatic activity of $\gamma$-secretase.

a
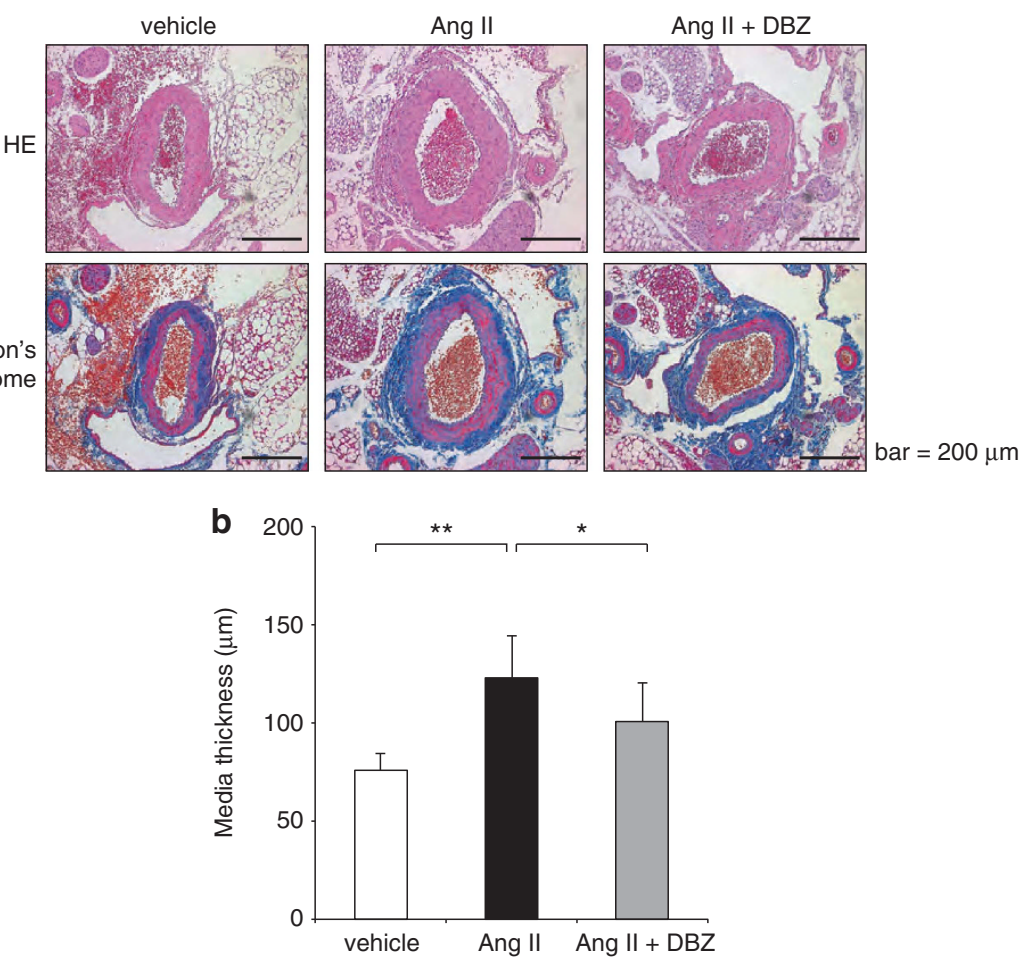

Figure 4 Ang II promotes vascular remodeling via activation of Notch signaling. (a) Representative hematoxylin and eosin (HE) staining (upper panels) and Masson's trichrome staining (lower panels) of the thoracic aortas of mice treated with vehicle, Ang II or Ang II/dibenzazepine (DBZ). Scale bars: 200 $\mu \mathrm{m}$. (b) Medial thickness of the abdominal aortas of mice treated with vehicle. Ang II or Ang II/DBZ ( $n=4$ sections from five to six mice in each group). The data are presented as the mean \pm s.e.m. ${ }^{*} P<0.05,{ }^{*} P<0.01$. 
Notch signaling has been reported to control the cell fate, proliferation, differentiation and migration of postnatal VSMCs. ${ }^{11,12,22}$ The established vascular target genes of the Notch signaling pathway include the Hes and Hey gene families. ${ }^{8,12}$ Interestingly, Notch 3 receptor signaling promoted the proliferation of VSMCs by decreasing mRNA expression of the cell-cycle inhibitor p27 Kip1 ${ }^{23}$ As p $27^{\mathrm{Kip} 1}$ is expressed abundantly in quiescent VSMCs and Ang II promotes proliferation particularly when the expression levels of $\mathrm{p} 27^{\mathrm{Kip} 1}$ are low, ${ }^{24}$ it is reasonable to hypothesize that Notch signal activation mediates the Ang II-induced proliferation of VSMCs via reduction of $\mathrm{p} 27^{\mathrm{Kip} 1}$ expression levels. Further studies are necessary to identify the Notch target genes responsible for mediating $\mathrm{AT}_{1}$ receptor-induced proliferation and migration of VSMCs.

In spite of the abundant literature supporting the crucial role of Notch signaling in cardiovascular development, ${ }^{25}$ the role of Notch signaling in the pathogenesis of cardiovascular remodeling under pathological conditions has not been extensively investigated. Studies using genetic disruption or activation of Notch signaling have shown that Notch signaling mediates cardiac repair and regeneration following myocardial infarction. ${ }^{26}$ Notch signaling has also been found to promote atherosclerosis, metabolic disorders and pulmonary vascular remodeling in animal models. ${ }^{27-29}$ A potential limitation of the present study is that $\gamma$-secretase inhibitors exert nonspecific effects on other type I transmembrane proteins (for example, amyloid precursor protein, ErbB4, CD44 and E-cadherin) that have been shown to be substrates for $\gamma$-secretase. ${ }^{18}$ As a followup to our finding that the $\mathrm{AT}_{1}$ receptor-Notch signaling pathway is involved in the pathogenesis of vascular remodeling, further studies using sophisticated genetic approaches will lead to a greater understanding of the functions and roles of the $\mathrm{AT}_{1}$ receptor-Notch signaling pathway in a wide variety of cardiovascular and metabolic diseases.

In conclusion, Notch signaling is activated as a consequence of the enhanced enzymatic activity of $\gamma$-secretase by $\mathrm{AT}_{1}$ receptor activation. This hierarchical pathway stimulates the proliferation and migration of VSMCs, and contributes to vascular remodeling in mice. Vascular remodeling is a crucial feature of end-organ damage associated with hypertension and atherosclerosis, which contributes to clinical morbidity and mortality. A growing body of evidence suggests that the use of $\mathrm{AT}_{1}$ receptor blockers leads to a significant decrease in mortality and morbidity in patients with cardiovascular complications. ${ }^{30,31}$ The $\mathrm{AT}_{1}$ receptor activates multiple downstream signaling pathways, and some novel $\mathrm{AT}_{1}$ receptor blockers function as biased ligands, which selectively activate only those pathways that lead to beneficial effects. $^{32,33}$ Elucidation of the molecular basis of the hierarchical $\mathrm{AT}_{1}$ receptor-Notch signaling pathway will therefore be helpful in developing novel $\mathrm{AT}_{1}$ receptor blockers with higher efficacy in preventing vascular remodeling.

\section{CONFLICT OF INTEREST}

The authors declare no conflict of interest.

\section{ACKNOWLEDGEMENTS}

We thank A Furuyama, Y Ohtsuki, and I Sakamoto for their excellent technical assistance. This work was supported in part by grants from the Japan Society for the Promotion of Science (KAKENHI 21229010, 23390213, and 24659390), and Health and Labor Sciences Research Grants (to IK and HA), and by the Japan Foundation for Applied Enzymology (to HA).
1 Paul M, Poyan Mehr A, Kreutz R. Physiology of local renin-angiotensin systems. Physiol Rev 2006; 86: 747-803.

2 Timmermans PB, Wong PC, Chiu AT, Herblin WF, Benfield P, Carini DJ, Lee RJ, Wexler RR, Saye JA, Smith RD. Angiotensin II receptors and angiotensin II receptor antagonists. Pharmacol Rev 1993; 45: 205-251.

3 Hunyady L, Catt KJ. Pleiotropic AT1 receptor signaling pathways mediating physiological and pathogenic actions of angiotensin II. Mol Endocrinol 2006; 20: 953-970.

4 Mehta PK, Griendling KK. Angiotensin II cell signaling: physiological and pathological effects in the cardiovascular system. Am J Physiol Cell Physiol 2007; 292: C82-C97.

5 Geisterfer AA, Peach MJ, Owens GK. Angiotensin II induces hypertrophy, not hyperplasia, of cultured rat aortic smooth muscle cells. Circ Res 1988; 62: 749-756.

6 Xi XP, Graf K, Goetze S, Fleck E, Hsueh WA, Law RE. Central role of the MAPK pathway in Ang II-mediated DNA synthesis and migration in rat vascular smooth muscle cells. Arterioscler Thromb Vasc Biol 1999; 19: 73-82.

7 Intengan HD, Schiffrin EL. Vascular remodeling in hypertension: roles of apoptosis, inflammation, and fibrosis. Hypertension 2001; 38: 581-587.

8 High FA, Epstein JA. The multifaceted role of Notch in cardiac development and disease. Nat Rev Genet 2008; 9: 49-61.

9 Kopan R, Ilagan MX. The canonical Notch signaling pathway: unfolding the activation mechanism. Cell 2009; 137: 216-233.

10 Guruharsha KG, Kankel MW, Artavanis-Tsakonas S. The Notch signalling system: recent insights into the complexity of a conserved pathway. Nat Rev Genet 2012; 13: 654-666.

11 Iso T, Hamamori Y, Kedes L. Notch signaling in vascular development. Arterioscler Thromb Vasc Biol 2003; 23: 543-553.

12 Morrow D, Guha S, Sweeney C, Birney Y, Walshe T, O'Brien C, Walls D, Redmond EM, Cahill PA. Notch and vascular smooth muscle cell phenotype. Circ Res 2008; 103: 1370-1382.

13 Yasuda N, Miura S, Akazawa H, Tanaka T, Qin Y, Kiya Y, Imaizumi S, Fujino M, Ito K, Zou Y, Fukuhara S, Kunimoto S, Fukuzaki K, Sato T, Ge J, Mochizuki N, Nakaya H, Saku K, Komuro I. Conformational switch of angiotensin II type 1 receptor underlying mechanical stress-induced activation. EMBO Rep 2008; 9: 179-186.

14 Qin Y, Yasuda N, Akazawa H, Ito K, Kudo Y, Liao CH, Yamamoto R, Miura S, Saku K, Komuro I. Multivalent ligand-receptor interactions elicit inverse agonist activity of AT(1) receptor blockers against stretch-induced AT(1) receptor activation. Hypertens Res 2009; 32: 875-883.

15 Kurooka H, Kuroda K, Honjo T. Roles of the ankyrin repeats and C-terminal region of the mouse notch1 intracellular region. Nucleic Acids Res 1998; 26 5448-5455.

16 Nishimura M, Isaka F, Ishibashi M, Tomita K, Tsuda H, Nakanishi S, Kageyama R. Structure, chromosomal locus, and promoter of mouse Hes2 gene, a homologue of Drosophila hairy and Enhancer of split. Genomics 1998; 49: 69-75.

17 Yasuda N, Akazawa H, Ito K, Shimizu I, Kudo-Sakamoto Y, Yabumoto C, Yano M, Yamamoto R, Ozasa Y, Minamino T, Naito AT, Oka T, Shiojima I, Tamura K, Umemura S, Paradis P, Nemer M, Komuro I. Agonist-independent constitutive activity of angiotensin II receptor promotes cardiac remodeling in mice. Hypertension 2012, 59: 627-633

18 Wong GT, Manfra D, Poulet FM, Zhang Q, Josien H, Bara T, Engstrom L, Pinzon-Ortiz M, Fine JS, Lee HJ, Zhang L, Higgins GA, Parker EM. Chronic treatment with the gamma-secretase inhibitor LY-411,575 inhibits beta-amyloid peptide production and alters lymphopoiesis and intestinal cell differentiation. J Biol Chem 2004; 279 12876-12882.

19 Zou Y, Akazawa H, Qin Y, Sano M, Takano H, Minamino T, Makita N, Iwanaga K, Zhu W Kudoh S, Toko H, Tamura K, Kihara M, Nagai T, Fukamizu A, Umemura S, liri T, Fujita T, Komuro I. Mechanical stress activates angiotensin II type 1 receptor without the involvement of angiotensin II. Nat Cell Biol 2004; 6: 499-506.

20 Farmery MR, Tjernberg LO, Pursglove SE, Bergman A, Winblad B, Naslund J. Partia purification and characterization of gamma-secretase from post-mortem human brain. $J$ Biol Chem 2003; 278: 24277-24284.

21 Ni Y, Zhao X, Bao G, Zou L, Teng L, Wang Z, Song M, Xiong J, Bai Y, Pei G. Activation of beta(2)-adrenergic receptor stimulates gamma-secretase activity and accelerates amyloid plaque formation. Nat Med 2006; 12: 1390-1396.

22 Sweeney C, Morrow D, Birney YA, Coyle S, Hennessy C, Scheller A, Cummins PM, Walls D, Redmond EM, Cahill PA. Notch 1 and 3 receptor signaling modulates vascular smooth muscle cell growth, apoptosis, and migration via a CBF-1/RBP-Jk dependent pathway. FASEB J 2004; 18: 1421-1423.

23 Campos AH, Wang W, Pollman MJ, Gibbons GH. Determinants of Notch-3 receptor expression and signaling in vascular smooth muscle cells: implications in cell-cycle regulation. Circ Res 2002; 91: 999-1006.

24 Braun-Dullaeus RC, Mann MJ, Ziegler A, von der Leyen HE, Dzau VJ. A novel role for the cyclin-dependent kinase inhibitor p27(Kip1) in angiotensin II-stimulated vascular smooth muscle cell hypertrophy. J Clin Invest 1999; 104: 815-823.

25 de la Pompa JL, Epstein JA. Coordinating tissue interactions: Notch signaling in cardiac development and disease. Dev Cell 2012; 22: 244-254.

$26 \mathrm{Li}$ Y, Hiroi Y, Liao JK. Notch signaling as an important mediator of cardiac repair and regeneration after myocardial infarction. Trends Cardiovasc Med 2010; 20: 228-231.

27 Aoyama T, Takeshita K, Kikuchi R, Yamamoto K, Cheng XW, Liao JK, Murohara T. Gamma-Secretase inhibitor reduces diet-induced atherosclerosis in apolipoprotein E-deficient mice. Biochem Biophys Res Commun 2009; 383: 216-221.

28 Fukuda D, Aikawa E, Swirski FK, Novobrantseva TI, Kotelianski V, Gorgun CZ, Chudnovskiy A, Yamazaki H, Croce K, Weissleder R, Aster JC, Hotamisligil GS, Yagita 
$\mathrm{H}$, Aikawa M. Notch ligand delta-like 4 blockade attenuates atherosclerosis and metabolic disorders. Proc Natl Acad Sci USA 2012; 109: E1868-E1877.

29 Qiao L, Xie L, Shi K, Zhou T, Hua Y, Liu H. Notch signaling change in pulmonary vascular remodeling in rats with pulmonary hypertension and its implication for therapeutic intervention. PLoS One 2012; 7: e51514.

30 Zaman MA, Oparil S, Calhoun DA. Drugs targeting the renin-angiotensin-aldosterone system. Nat Rev Drug Discov 2002; 1: 621-636.

31 Dell'italia LJ. Translational success stories: Angiotensin receptor 1 antagonists in heart failure. Circ Res 2011; 109: 437-452.
32 Rajagopal K, Whalen EJ, Violin JD, Stiber JA, Rosenberg PB, Premont RT, Coffman TM, Rockman HA, Lefkowitz RJ. Beta-arrestin2-mediated inotropic effects of the angiotensin II type 1A receptor in isolated cardiac myocytes. Proc Natl Acad Sci USA 2006; 103: 16284-16289.

33 Boerrigter G, Lark MW, Whalen EJ, Soergel DG, Violin JD, Burnett JC Jr. Cardiorenal actions of TRV120027, a novel ss-arrestin-biased ligand at the angiotensin II type I receptor, in healthy and heart failure canines: a novel therapeutic strategy for acute heart failure. Circ Heart Fail 2011; 4: 770-778.

Supplementary Information accompanies the paper on Hypertension Research website (http://www.nature.com/hr) 